\title{
On the Chemical Aspects of the Biodelignification of Wheat Straw with Pycnoporus sanguineus and Its Combined Effects with the Presence of Candida tropicalis
}

Nian-Jie Feng ${ }^{\text {a }}$, Hua-Min Zhai ${ }^{a^{*}}$, Yuan-Zong Lai ${ }^{\mathrm{b}}$

${ }^{a}$ College of Chemical Engineering, Nanjing Forestry University, Nanjing 210037, China

${ }^{\mathrm{b}}$ Department of Paper and Bioprocess Engineering Empire State Paper Research Institute, SUNY College of Environmental Science and Forestry, Syracuse, NY 13210, USA

\section{${ }^{*}$ Corresponding Author}

Tel./fax: +86 25 85428906; E-mail address: hzhai@njfu.edu.cn

Abstract: Pycnoporus sanguineus $(\mathrm{Ps})^{1}$ and Candida tropicalis $(\mathrm{Ct})$ can selectively degrade the lignin and hemicellulose in lignocellulosic cells respectively; Ps-Ct mixed fermentation may improve the multiphase reaction performance of lignin in the cell walls. Alkaline nitrobenzene oxidation, ozonation and infrared spectroscopy, which are the in-situ analytical techniques of lignin in the cells, were used to characterize the delignification kinetics, the reactions of the non-condensed, $\beta-\mathrm{O}-4$ structures and their stereochemistry of lignin in wheat straw in Ps and Ps-Ct fermentations. Results indicated that the biodelignification processes in Ps and Ps-Ct fermentations of wheat straw, being divided into a fast phase and a following slow phase, had the characteristics of a pseudo-first-order reaction in both the phases. The lignin reaction pathways in Ps and Ps-Ct mainly included the cleavage of ring, $\mathrm{C}_{\alpha}-\mathrm{C}_{\beta}, \beta-\mathrm{O}-4$, and the cleavage and polymerization of 5-5'. Compared with Ps fermentation, Ps-Ct fermentation enhanced the

\footnotetext{
${ }^{1}$ ABBREVIATIONS

Ps, Pycnoporus sanguineus; $\mathrm{Ct}$, Candida tropicalis
} 
biodegradation of condensed, $\beta-\mathrm{O}-4$ structures and threo $\beta-\mathrm{O}-4$ structures in the lignin in the fast phase. A proposal scheme of biodelignification by Ps and Ps-Ct is outlined for the first time.

These results will be helpful for the understanding and application of lignocellulosic biomass by mixed fermentations.

Keywords: Pycnoporus sanguineus; Candida tropicalis; wheat straw; lignin; biodelignification chemistry; chemical structure

\section{INTRODUCTION}

Lignin has a significant and largely unrealized potential as a source for the sustainable production of fuels and bulk high-value chemicals. One way of the efficient utilization of lignin requires its depolymerization by laccase. On the other hand, lignin removal from biomass helps enhance the efficiency of cellulose and hemicellulose hydrolysis, and therefore, facilitates the utilization of the carbohydrate portion of biomass in production of cellulosic ethanol and other biofuels and chemicals (Siqueira et al., 2013).The ability of laccase to attack and degrade lignin is closely in conjunction with laccase mediators. Laccases (benzenediol: oxygen oxidoreductases, EC 1.10.3.2) are blue multicopper oxidases that catalyze the oxidation of an array of aromatic substrates concomitantly with the reduction of molecular oxygen to water. In most cases the laccases are restricted to the oxidation of the phenolic lignin moiety, which represents less than $20 \%$ of typical lignin polymers. The presence of certain small-molecular weight compounds acting as redox mediators expands the catalytic activity of laccases towards more recalcitrant compounds such as non-phenolic lignin units (Arzola et al., 2009). The efficiency of laccase-mediator systems (LMS) to degrade recalcitrant compounds has been demonstrated, but the high cost and possible toxicity of artificial mediators still hamper their industrial application (Cañas and Camarero, 2010). For these reasons, many studies have focused on searching for 
alternative mediators, which could present environmental and economic advantages. Initial attempts were directed towards fungal metabolites as natural laccase substrates. Eggert et al. (1995) found that 3-Hydroxyanthranilic acid (3-HAA), a secondary metabolite synthesized by the ligninolytic fungus Pycnoporus, was shown to mediate the biodelignification by laccase. Subsequently, Eggert et al. (1996) also demonstrated that 3-HAA can mediate the oxidation of non-phenolic substrates (veratryl glycerol- $\beta$-guaiacyl ether) by laccase. Due to the economic and environmental advantages, Pycnoporus sanguineus with the natural laccase mediator, 3-HAA, is attractive for bioconversion of lignocellulosic biomass as compared with other technologies, e.g. kraft pulping with low yield and water pollution (Kleppe, 1970).

Wheat straw, mainly composed of cellulose, hemicellulose and lignin, is an important lignocellulosic biomass for the future of bioenergy and biochemicals (Himmel et al., 2007). However, it still cannot be effectively used (Menon and Rao, 2012). One reason precluding its utilization is the complex organizational structure of the lignocellulosic matrix, which increases natural biological resistance of cell wall, making lignocellulose biotransformation a great challenge (Camarero et al., 2014). In the process of lignin biosynthesis, lignin is gradually deposited in the cell wall, where it mingles and connects with hemicellulose. Meanwhile, a composite structure is formed between the above two components and cellulose (Niu et al., 2009). Therefore, the biodelignification is important for bioconversion of lignocellulosic biomass. Our research has indicated that Pycnoporus sanguineus NFZH-1 (Ps) can selectively degrade the lignin in wheat straw (Feng et al., 2014). However, it could be extremely difficult for single lignin-degrading fungi to rapidly conduct bulk biodegradation. It is possible that a mixed fermentation of carbohydrate-degrading and lignin-degrading fungi could reduce this bottleneck in the biodelignification and conversion of lignocellulosic biomass (Boonyuen et al., 2014). 
Degradation and dissolution of lignocellulose-associated carbohydrates from the cell wall improve cell wall porosity and permeability, which would facilitate the growth of lignin-degrading fungi and penetration of the associated enzymes, benefitting the biodegradation of lignin in the lignocellulosic biomass. Candida tropicalis AS-2.637 (Ct) is a typical pentose-fermenting fungus, and cannot directly degrade lignin, while the metabolism of the five-carbon sugars can facilitate the biodegradation of hemicellulose in the lignocellulosic cells (Roberto et al., 2003). Ps-Ct mixed fermentation may improve the multi-phase reaction performance of lignin biodegradation in lignocellulosic cells.

Wheat straw lignin is composed of guaiacyl $(\mathrm{G})$, syringyl $(\mathrm{S})$ and hydroxyphenyl $(\mathrm{H})$ structural units, which are connected with ether bonds and C-C bonds (Freudenberg, 1959). During alkaline pulping, the nucleophilic reagent attracts the $\mathrm{C}_{\alpha}$ site of lignin phenylpropanes and breaks the $\beta-\mathrm{O}-4$ structures through neighboring group participation. Molecular fragmentation and increased hydrophilicity make the lignin degradation (Kleppe, 1970). Unlike alkaline pulping delignification, many complex oxidation reactions occur during the biodelignification. The reactions known to occur include a) the cleavage of $\beta$-O-4 linkages, b) the cleavage of $\mathrm{C}_{\alpha}-\mathrm{C}_{\beta}$ side chain bonds, c) the oxidative cleavage of aromatic rings, $d$ ) demethylation, and e) numerous other oxidative transformations (Crawford and Crawford, 1984). Prior studies indicated that Ps-Ct mixed fermentation increased the biodelignification by $15.2 \%$ (Feng et al., 2015). However, the biodelignification chemistry of wheat straw through the Ps and Ps-Ct fermentations remains unclear. An undrstanding on the chemical aspects of the biodelignification of wheat straw with Ps and its combined effects with the presence of $\mathrm{Ct}$ are necessary for improving the bioconversion and utilization of lignocellulosic biomass. In-situ analytical techniques, including biodelignification kinetics analysis, nitrobenzene oxidation (NO), 
ozonation (Z), and Fouruer Transform infrared (FTIR) spectra, were conducted for the purpose.

\section{MATERIALS AND METHODS}

\subsection{Materials}

Wheat straw (Triticum aestivum c.v.yang No.4), was collected from Nanjing, China. The straw was cleaned by the removal of the leaves, spikes, sheaths, and fragments, subsequently ground in a Wiley mill, and obtained $0.25-0.42 \mathrm{~mm}$ fraction. The fraction was treated with $2 \%$ $\mathrm{NaOH}$ solution (weight/volume ratio of $1: 4$ ) at $121^{\circ} \mathrm{C}$ for $30 \mathrm{~min}$ for its uniformity biodegradation. The alkali-treated wheat straw was cooled, washed with distilled water until pH 7, and air-dried to a constant weight for fermentations.

N,O-Bis (trimethylsilyl) trifluoroacetamide with trimethylchlorosilane (BSTFA+TMCS) was purchased from SIGMA-ALDRICH, Co., (St, Louis, USA). Potatoes were obtained from local market. All other chemicals were from Chinese sources. BSTFA+TMCS and KBr were HPLC grade, and all other chemicals were analytical grade.

Isolation and identification of the $P$. sanguineus NFZH-1 was described in our previous paper (Feng et al., 2014), Ps was deposited in the Culture Collection of Wood Rot Fungi, Nanjing Forestry University, China; C. tropicalis AS-2.637 was obtained from Institute of Microbiology, Academia Sinica, Beijing, China. Both strains were maintained on potato dextrose agar (PDA) slants at $4^{\circ} \mathrm{C}$. PDA medium contains (per liter) $200 \mathrm{~g}$ potato, $20 \mathrm{~g}$ glucose and $20 \mathrm{~g}$ agar.

\subsection{Fermentation}

$5 \mathrm{~g}$ alkali-treated wheat straw powder (oven dry) and $12 \mathrm{~mL}$ Kirk nutrient solution were mixed in $250 \mathrm{~mL}$ Erlenmeyer flask, followed by sterilization at $121^{\circ} \mathrm{C}$ for $60 \mathrm{~min} .10 .0 \mathrm{~g}$ glucose $0.44 \mathrm{~g}$ ammonium tartrate, $6.0 \mathrm{~g} \mathrm{KH}_{2} \mathrm{PO}_{4}, 4.1 \mathrm{~g} \mathrm{MgSO}_{4} \cdot 7 \mathrm{H}_{2} \mathrm{O}, 0.3 \mathrm{~g} \mathrm{CaCl}_{2}, 0.2 \mathrm{~g} \mathrm{NaCl}, 0.1 \mathrm{~g}$ $\mathrm{MnSO}_{4} \cdot \mathrm{H}_{2} \mathrm{O}, 6 \mathrm{mg}$ vitamin $\mathrm{B}_{1}$ and $0.5 \mathrm{~mL}$ Tween-80 were contained in each liter of modified 
Kirk medium. 7-day-old stains were inoculated into sterilized flasks. The inoculated Erlenmeyer flask was incubated at $28^{\circ} \mathrm{C}$ without shaking for $5,10,20,30$, and 40 days' fermentations. Then the biodegraded samples (residues) were washed with distilled water. The residues were air dried for analysis of lignin content and structure. The yield was estimated as a percentage by the oven-dried weight ratio of biodegraded residue and original alkali-treated wheat straw.

To prepare Ps fermentation, four Ps colonies (10 mm diameter for each colony of Ps) were inoculated; to prepare Ps-Ct fermentation, two Ps colonies and two Ct colonies (10 mm diameter for each colony of Ps and $\mathrm{Ct}$ ) were inoculated. Ps and Ps-Ct fermentations were both conducted in triplicate.

\subsection{Determination of Lignin Content}

The washed residues were measured for the lignin content according to standard methods from the Technical Association of the Pulp and Paper Industry (TAPPI, 1995). These protocols were for Klason lignin (T222om-88) and acid-soluble lignin (T13wd-74). The lignin content in this study was the sum of Klason lignin and acid-soluble lignin. Alkali-treated wheat straw contained 16.2\% lignin (Klason lignin 14.9\% and acid-soluble lignin 1.3\%).

\subsection{Alkaline Nitrobenzene Oxidation}

Alkaline nitrobenzene oxidation was performed according to previous literature with modification (Ma et al., 2012). Wheat straw samples (air dry) containing $10 \mathrm{mg}$ lignin was sealed in a stainless steel autoclave with $2 \mathrm{M} \mathrm{NaOH}(3.2 \mathrm{~mL})$ and nitrobenzene $(0.2 \mathrm{~mL})$ and heated at $170^{\circ} \mathrm{C}$ for $3 \mathrm{~h}$. After cooling with tap water, 2,6-dimethoxyphenol (2.5 mg) was added as an internal standard. The reaction mixtures with the internal standard were transferred to $250 \mathrm{~mL}$ separatory funnel, washed with dichloromethane $(20 \mathrm{~mL} \times 3)$, and acidified with $18 \% \mathrm{HCl}$. The

acidified aqueous layer was extracted with dichloromethane $(20 \mathrm{~mL} \times 3)$. The combined organic 
layer was dried overnight with anhydrous $\mathrm{MgSO}_{4}$. The organic extracts were filtered through Whatman No. 54 filter paper, concentrated under reduced pressure at $40^{\circ} \mathrm{C}$ and dried overnight over $\mathrm{P}_{2} \mathrm{O}_{5}$. The dried products were dissolved in pyridine $(300 \mu \mathrm{L})$ and trimethylsilylated with BSTFA+TMCS $(100 \mu \mathrm{L})$ at room temperature for $30 \mathrm{~min}$. The trimethylsilyl derivatives were analyzed by gas chromatography with a flame ionization detector (GC-FID, GC9800, China). The analytical column was a fused-silica capillary column (SGE Analytical Science BP5, 0.25 mm i.d. $\times 30 \mathrm{~m})$. The nitrogen was used as a carrier gas with flow rate of $1 \mathrm{~mL} / \mathrm{min}$. The column temperature programme was $160^{\circ} \mathrm{C}(0 \mathrm{~min}) ; 160-260^{\circ} \mathrm{C}\left(4^{\circ} \mathrm{C} / \mathrm{min}\right.$, hold time of $\left.3 \mathrm{~min}\right)$. The injector and detector temperatures were maintained at 260 and $270^{\circ} \mathrm{C}$.

Content of non-condensed lignin structural units $(\mathrm{G}, \mathrm{S}$ and $\mathrm{H})$ was calculated according to Formula (1). The nitrobenzene oxidation products (NOP) were the sum of three kinds of lignin units. $37.4 \%$ (mol) NOP (G unit 18.6\%, S unit $16.6 \%$ and $\mathrm{H}$ unit $2.2 \%$ in mol) were found in alkali-treated wheat straw.

$$
\text { Content }(\%, \mathrm{~mol})=\frac{A_{s} \times \mathrm{C} \times W_{i} \times \mathrm{M}}{A_{i} \times \mathrm{M}_{\mathrm{s}} \times L} \times 100
$$

Where $\mathrm{A}_{\mathrm{s}}$ and $\mathrm{A}_{\mathrm{i}}$ represent the peak area of the product and the internal standard respectively, $\mathrm{C}$ is the conversion factor including extraction efficiency and response factor of the particular product toward the detector, $\mathrm{W}_{\mathrm{i}}$ is the quantity of the internal standard added (mg), $\mathrm{M}$ is the molar mass of the $\mathrm{C}_{9}$ lignin unit $\left(\mathrm{C}_{9} \mathrm{H}_{6.99} \mathrm{O}_{2.76}\left(\mathrm{OCH}_{3}\right)_{1.11}, \mathrm{M}=237 \mathrm{~g} \cdot \mathrm{mol}^{-1}\right)$ (Zhai et al., 1992), $M_{s}$ is the molar mass of the corresponding lignin unit ( $G, S$ or $\left.H\right)$, and $L$ is the weight of lignin used (mg)

\subsection{Ozonation}

The ozonation employed in this work was based on previous reports with minor modification (Akiyama et al., 2005). Wheat straw samples (air dry) containing $20 \mathrm{mg}$ lignin were 
suspended in $50 \mathrm{~mL}$ of $\mathrm{AcOH}-\mathrm{H}_{2} \mathrm{O}-\mathrm{MeOH}$ (80:15:5 by volume) in an ice bath. Oxygen containing ca. 3\% ozone (GS-Y20, Guoli ozone, China) was bubbled into suspension at a rate of

$500 \mathrm{~mL} \cdot \mathrm{min}^{-1}$ for $2 \mathrm{~h}$ with stirring. After removing residual ozone, $0.1 \mathrm{M}$ sodium thiosulfate $(0.3$ $\mathrm{mL}$ ) was added. The solution was filtered through a grade- 2 sintered-glass funnel, removed under reduced pressure at $40^{\circ} \mathrm{C}$ and traces of acetic acid were removed by repeated evaporation with small amounts of distilled water $(10 \mathrm{~mL} \times 2)$. The obtained samples were saponified with $0.1 \mathrm{M} \mathrm{NaOH}(20 \mathrm{~mL})$ under a nitrogen atmosphere and then at room temperature overnight. Erythritol (2 mg) was added as internal standard. The saponified solution was passed through a column filled with $30 \mathrm{~mL}$ of cation-exchange resin (Dowex $50 \mathrm{~W}-\mathrm{X} 4, \mathrm{NH}_{4}{ }^{+}$form), and the column was washed with distilled water until the $\mathrm{pH} 7$ of the eluent, resulting in a total volume of $300 \mathrm{~mL}$. The collected eluent was concentrated under reduced pressure at $40^{\circ} \mathrm{C}$ and the samples were dried overnight under vacuum over $\mathrm{P}_{2} \mathrm{O}_{5}$, dissolved in pyridine $(200 \mu \mathrm{L})$ and trimethylsilylated with BSTFA+TMCS $(200 \mu \mathrm{L})$ at $70^{\circ} \mathrm{C}$ for $60 \mathrm{~min}$. The trimethylsilyl derivatives were analyzed by GC-FID (GC9800, China). The column temperature programme was $120^{\circ} \mathrm{C}(0 \mathrm{~min}) ; 120-260^{\circ} \mathrm{C}\left(4^{\circ} \mathrm{C} / \mathrm{min}\right.$, hold time of $\left.3 \mathrm{~min}\right)$, other conditions were the same as described in alkaline nitrobenzene oxidation.

Content of erythronic acid (E) and threonic acid (T) was calculated according to Formula (1), where $M_{s}$ represent the molar mass of the $E(T)$. The ozonation products $(E+T)$ were the sum of E and T. $15.11 \%$ (mol) ozonation products (E 8.7\% and T 6.4\% in mol) were found in alkali-treated wheat straw.

\subsection{Infrared Spectroscopy}

Fourier Transform infrared (FTIR) spectra of the samples were recorded on a Nicolet750 spectrophotometer in the range of $400-4000 \mathrm{~cm}^{-1}$ with a resolution of $4 \mathrm{~cm}^{-1} . \mathrm{KBr}$ disc $(13 \mathrm{~mm})$ 
containing $1 \%$ finely ground sample was used for measurement. The spectra of samples were obtained by subtracting the spectrum of $\mathrm{KBr}$.

\subsection{Removal Calculation and Statistics}

Removals of all lignin oxidation products (G, S, H, NOP, E, T and E+T) were calculated with Formula (2):

$$
\operatorname{Removal}(\%)=\frac{\mathrm{C}_{\mathrm{a}}-\left(Y \times C_{b}\right)}{\mathrm{C}_{\mathrm{a}}} \times 100
$$

Where $\mathrm{Y}$ is the yield of the wheat straw biodegradation, $\mathrm{C}_{\mathrm{a}}$ and $\mathrm{C}_{\mathrm{b}}$ represent lignin oxidation product content of the wheat straw and the biodegraded wheat straw, respectively.

The tests were done in triplicate, and the data were analyzed by an analysis of variance.

\section{RESULTS AND DISCUSSION}

\subsection{Kinetics of Biodegradation}

Figure 1 shows the relationship between the biodelignification of wheat straw and the time in the Ps and Ps-Ct fermentations. In both cases, biodelignification process can be divided to two phases, namely a fast phase in the initial 10 days, and a slow one from day 10 to day 40 . The lignin removals of the two phases were $38.7 \%$ and $9.2 \%$ for Ps, $44.7 \%$ and $8.2 \%$ for Ps-Ct. Compared with the Ps fermentation, the total biodelignification of the Ps-Ct fermentation was increased by $5.0 \%$, and the biodelignification in the fast phase was increased by $6.0 \%$, indicating an obvious increase of biodelignification with the presence of $\mathrm{Ct}$ in the fast phase.

For the biodelignification kinetics, the relationship between logarithmic lignin content $\left(\mathrm{LgC}_{\mathrm{L}}\right)$ and time was plotted (Fig. 2). In Ps and Ps-Ct fermentations, the biodelignification kinetic curves both showed linear relationships in two phases. On one hand, it indicated that the biodelignification was a pseudo-first-order reaction; on the other hand, the different slopes of the curves suggested that the biodelignification process was divided into the fast phase (day 0 to day 
10) and the slow phase (day 10 to day 40). The biodelignification rate constants of two phases were $0.021 /$ day $\left(\mathrm{k}_{\mathrm{p} 1}\right)$ and $0.0027 /$ day $\left(\mathrm{k}_{\mathrm{p} 2}\right)$ for Ps, $0.026 /$ day $\left(\mathrm{k}_{\mathrm{pc} 1}\right)$ and $0.0023 /$ day $\left(\mathrm{k}_{\mathrm{pc} 2}\right)$ for Ps-Ct. Compared with the Ps, the biodelignification rate of fast phase was significantly increased $\left(\mathrm{k}_{\mathrm{pc} 1}=\right.$ $0.026 /$ day $>\mathrm{k}_{\mathrm{p} 1}=0.021 /$ day) duo to the presence of $\mathrm{Ct}$.

Compared with Ps process, a combination of lignocellulosic degrading enzyme system, including laccase, endoglucanase and xylanase, was formed in Ps-Ct process, and their activities were also increased (Feng et al., 2015). The combination enzymes improved the degrading ability to the components in the wheat straw cell walls; and the degradation and dissolution of carbohydrate improved the porosity of the cell wall. The porosity modification of cell wall increased the enzymes permeability, and strengthened the biodelignification.

\subsection{Biodegradation of Non-condensed Lignin}

Alkaline nitrobenzene oxidation is not only important in terms of the characterization of lignin by providing information on the relative amounts of the uncondensed lignin units, but also in terms of the taxonomy of vascular plants (Chen, 1992). When applied to wheat straw and treated ones, this procedure converts the lignin to identifiable aromatic fragments, which are mostly a mixture of aromatic aldehydes comprising vanillin (G), syringaldehyde (S) and p-hydroxybenzaldehyde $(H)$. In this study, the amounts of each aldehyde were used to determine the composition and structure of the lignin in wheat straw, and their estimation is thus of crucial importance in structural studies (Chang and Allan, 1971).

Figure 3a shows the relationship between the yield and ratio of NOP and time in Ps and Ps-Ct fermentations. In both cases, non-condensed lignin biodegradation was composed of the two phases, fast and slow biodelignification phases. In two phases, NOP removals were $23.8 \%$ and $4.3 \%$ for Ps, $25.6 \%$ and $4.0 \%$ for Ps-Ct. The NOP yields of Ps and Ps-Ct fermentations were 
comparable with similar changing trends, without detection of any enhancing effects from Ps-Ct fermentation on the biodegradation of non-condensed lignin.

The reductions in NOP yield mainly suggested that non-condensed lignin with alkylaryl ether linkage was degraded. Taking into account the biodelignification (Fig. 1) and the associated kinetic curve (Fig. 2) doubly confirmed that Ps-Ct fermentation enhanced wheat straw biodelignification. It can be inferred that Ps-Ct fermentation is better suited to specifically promote condensed lignin biodegradation than Ps fermentation. This effect could be attributed to the distribution of condensed lignin in cell wall, the presence of the combination of degrading enzymes generated from Ps-Ct process, which improved the accessibility and reactivity of enzymes and strengthened outward diffusion of degradation products. It is generally true that carbon-to-carbon bonds are stable to other microorganisms (Ander, 1990). In alkaline pulping processes, the stability is also found, and additional condensed lignins form (Marton, 1971). Ps-Ct fermentation promoted the biodegradation of condensed lignin with C-C bonds, and hopefully these findings are beneficial to enhancing degradation of residual lignin in the alkaline pulp.

\subsection{Biodegradation of $\mathbf{G}, \mathbf{S}$ and $\mathbf{H}$ Units}

Figure $3 b$ shows the relationship between NOP from $G$ unit in the residues and time in Ps and Ps-Ct fermentations. In Ps fermentation, the removals of G unit in the fast phase and the slow phase were $33.9 \%$ and $3.2 \%$. In Ps-Ct fermentation, the removals of G unit in the fast phase and the slow phase were $34.4 \%$ and $3.1 \%$ respectively, indicating that biodegradation of uncondensed G unit in Ps and Ps-Ct fermentations were not obviously different.

Figure $3 \mathrm{c}$ shows the relationship between NOP from $\mathrm{S}$ unit in the residues and time in Ps and Ps-Ct fermentations. In Ps fermentation, the removals of S unit in the fast phase and the slow 
phases were $16.3 \%$ and 5.9\%. In Ps-Ct fermentation, the removals of S unit in the fast phase and the slow phase were $16.8 \%$ and $5.9 \%$ respectively. These data indicated that biodegradations of uncondensed S unit in Ps and Ps-Ct fermentations were comparable.

Figure 3d shows the change of non-condensed S/G ratio in the residues in Ps and Ps-Ct fermentations. The S/G ratio changes showed same trend in Ps and Ps-Ct fermentations. An increase of $\mathrm{S} / \mathrm{G}$ ratio was observed in the fast phase, $\mathrm{G}$ unit biodegradation mainly occurred in this phase, while $S / G$ ratio remained stable in the following slow phase. $S$ unit was usually preferentially degraded in both biodegradation (Munk et al., 2015) and alkaline delignification (Marton, 1971), which was different from the results of the present study. The difference may be attributed to alkali-soluble $\mathrm{S}$ unit which was dissolved in the alkali pretreatment of wheat straw before the fermentations.

Figure 3e shows the NOP from $\mathrm{H}$ unit change in the residues in Ps and Ps-Ct fermentations. In Ps fermentation, no significant $\mathrm{H}$ unit biodegradation was observed in both the phases. However, in Ps-Ct fermentation, $17.0 \% \mathrm{H}$ unit was degraded in the fast phase, but no significant biodegradation of $\mathrm{H}$ unit was observed in the slow phase. In comparison with Ps fermentation, uncondensed $\mathrm{H}$ unit biodegradation in the fast phase was promoted with the presence of $\mathrm{Ct}$, which increased the biodelignification of wheat straw.

Figure $3 \mathrm{f}$ shows the non-condensed $\mathrm{H} / \mathrm{G}$ ratio change in the residues in Ps and Ps-Ct fermentations. In both cases, the biodegradation was dominated by $\mathrm{G}$ unit in two phases, which was reflected by an increase of $\mathrm{H} / \mathrm{G}$ ratio. The increasing in the fast and slow phases was $58.3 \%$ and $8.4 \%$ for Ps, $26.4 \%$ and $10.6 \%$ for Ps-Ct. The $\mathrm{H} / \mathrm{G}$ ratio in the fast phase was reduced in Ps-Ct fermentation as compared with Ps fermentation, indicating that the uncondensed $\mathrm{H}$ unit biodegradation was promoted by Ps-Ct fermentation. 


\subsection{Biodegradation of $\beta-O-4$ Structures}

Arylglycerol- $\beta$-aryl ether type structures ( $\beta$-O-4 structures) are predominant linkage types in lignin. This linkage type can either be in the erythro (E) or threo (T) forms since its three-carbon side chain contains two asymmetric carbons (Akiyama et al., 2003). The $\beta-\mathrm{O}-4$ structures in the form of $\mathrm{E}$ and $\mathrm{T}$ and their stereochemistry can be characterized by ozonation, and it is available and effective for the determination of the frequency of these different side chains or for characterization of their stereochemistry (Sarkanen et al., 1992).

Figure 4a shows the yield variations of $\beta$-O-4 structures in the residues in Ps and Ps-Ct fermentations. In both cases, the biodegradation of $\beta-\mathrm{O}-4$ structures was described as a fast phase and a slow phase. The $\beta-\mathrm{O}-4$ structural biodegradations in two phases were $23.8 \%$ and $6.0 \%$ for Ps, $32.6 \%$ and $12.2 \%$ for Ps-Ct. Compared with Ps fermentation, the removal of $\beta-\mathrm{O}-4$ structures with Ps-Ct fermentation was increased by $15.0 \%$, among which $8.8 \%$ and $6.2 \%$ were increased in the fast and the slow phases, respectively.

If the oxidation is limited to phenolic subunits, then bulk delignification from wheat straw cell wall is unlikely, as this requires that many bonds of the three-dimensional polymer are broken. Moreover, steric hindrance formed by carbohydrates in the cell wall prevents the lignin-degrading fungi or enzymes from easily penetrating fiber cells, thus inhibiting lignin molecular fragmentation by the oxidation. In Ps-Ct fermentation, the combinations of lignocellulosic degrading enzymes, including laccase, endoglucanase and xylanase, were generated and positively degraded the carbohydrates from the cell wall. The carbohydrate dissolution created more porosity with the cell wall, which in turn improved the laccase penetration into the cell wall and enhanced the biodegradation, $\beta-\mathrm{O}-4$ structure breakage and lignin molecular fragmentation, of the lignin and outward diffusion of degraded products. 


\subsection{Stereochemistry of Biodelignification}

Figure $4 \mathrm{~b}$ shows the ozonation yield of E-form lignin in the residues in Ps and Ps-Ct fermentation processes. In Ps fermentation, the removals of E-form lignin in the fast phase and the slow phase were $41.4 \%$ and $5.7 \%$ respectively. In Ps-Ct fermentation, the removals of E-form lignin in the fast phase and the slow phase were $42.6 \%$ and $11.5 \%$ respectively, representing an increase by $1.2 \%$ and $5.8 \%$ in the fast phase and the slow phase respectively as compared with Ps fermentation.

Figure $4 \mathrm{c}$ shows the ozonation yield of T-form lignin in the residues in Ps and Ps-Ct fermentation processes. In Ps fermentation, the removal of T-form lignin showed only one phase, and a $7.9 \%$ biodegradation was found, including $1.4 \%$ in $0-10$ days and $5.6 \%$ in $10-40$ days. In Ps-Ct fermentation, the removals of T-form lignin in the fast phase and the slow phase were $18.9 \%$ and $13.0 \%$ respectively, indicating the increase by $17.5 \%$ and $7.4 \%$ in the fast phase and the slow phase respectively and an increase by $24.9 \%$ for the whole fermentation process as compared with Ps fermentation.

Figure $4 \mathrm{~d}$ shows the relationship between the E/T ratio in the residues and time in Ps and Ps-Ct fermentations. In both cases, the biodegradation of E-form lignin occurred in both the fast and slow phases, with the observed E/T ratio decreasing. The decreasing in two phases showed $40.4 \%$ and $2.2 \%$ for Ps, $29.3 \%$ and $3.4 \%$ for Ps-Ct. The E/T ratio in the fast phase increased in Ps-Ct fermentation as compared with Ps fermentation, implying that T-form lignin biodegradation was promoted by Ps-Ct fermentation.

Stereochemistry studies the arrangement of atoms in molecules or groups of atoms and its influence on physical and chemical properties of molecules (Rebek, 2005). Lignin contains a pair of $\mathrm{E}$ and $\mathrm{T}$ isomers. Shimizu et al. (2012) have also reported that the $\beta$-O-4 bonds of the $\mathrm{E}$ isomer 
are cleaved faster than those of $\mathrm{T}$ isomer under alkaline conditions. Due to steric hindrance and intermolecular hydrogen bonding, T-form is more stable and difficult to be degraded under alkaline conditions (Ueda et al., 2015). T-form degradation is promoted in Ps-Ct fermentation, which could be an important complementarity to alkaline delignification process.

\subsection{Infrared Spectra}

Band assignments in the FTIR spectra are indicated as shown in Figure 5 and Table 1. Figure 5(a) is FTIR of alkaline-treated wheat straw, Figure 5(b) and Figure 5(c) are FTIR of wheat straw degraded by Ps and Ps-Ct fermentations for 40 days, respectively.

FTIR characteristic bands for alkaline-treated wheat straw: 1) $3426 \mathrm{~cm}^{-1}$ is assigned to the stretch of OH groups; 2) 2921 and $2892 \mathrm{~cm}^{-1}$ are attributed to $\mathrm{C}-\mathrm{H}$ stretch in $\mathrm{CH}_{3}$ and $\mathrm{CH}_{2}$ groups; 3) $1654 \mathrm{~cm}^{-1}$ is attributed to conjugated $\mathrm{C}=\mathrm{O}$ stretch; 4) The aromatic ring vibration occurs at 1608,1512 and $1427 \mathrm{~cm}^{-1}$; 5) $1465 \mathrm{~cm}^{-1}$ indicates the $\mathrm{C}-\mathrm{H}$ deformations and aromatic ring vibration; 6) $1380 \mathrm{~cm}^{-1}$ is aliphatic $\mathrm{C}-\mathrm{H}$ stretch in $\mathrm{CH}_{3}$ group; 7) The aromatic ring breathing occurs at $1267 \mathrm{~cm}^{-1} ; 8$ ) The shoulder at $1165 \mathrm{~cm}^{-1}$, corresponding to $\mathrm{C}=\mathrm{O}$ in an ester group, gives signals for typical GSH-lignin; 9) The band at $1139 \mathrm{~cm}^{-1}$, corresponding to aromatic $\mathrm{C}-\mathrm{H}$ in-plane deformation, is a typical structure of $\mathrm{G}$ unit; 10) $1085 \mathrm{~cm}^{-1}$ is $\mathrm{C}-\mathrm{O}$ deformation in secondary alcohols and aliphatic ethers; 11) $896 \mathrm{~cm}^{-1}$ is aromatic out-of-plane C-H blending. These results were consistent with other study (Pandey and Pitman, 2003; Sun et al., 2005a, 2005b; Tejado et al., 2007; Zhang et al., 2007).

Table 1. Band assignments in the FTIR spectra

\begin{tabular}{cc}
\hline Wavenumbers $\left(\mathrm{cm}^{-1}\right)$ & Band Origin, Short Comments \\
\hline 3426 & $\mathrm{OH}$ stretch \\
2921,2892 & $\mathrm{C}-\mathrm{H}$ stretch in $\mathrm{CH}_{3}$ and $\mathrm{CH}_{2}$ \\
1654 & $\mathrm{C}=\mathrm{O}$ stretch \\
1608 & Aromatic skeletal vibration plus $\mathrm{C}=\mathrm{O}$ stretch \\
1512 & Aromatic skeletal vibration \\
\hline
\end{tabular}




\begin{tabular}{cc}
\hline 1465 & C-H deformation and aromatic skeletal vibration \\
1427 & Aromatic skeletal vibration combined with C-H in-plane deform \\
1380 & Aliphatic C-H stretch in $\mathrm{CH}_{3}$ \\
1327 & G ring condensed, G ring substituted in pos. 5 \\
1267 & Aromatic ring breathing \\
1165 & $\mathrm{C}=\mathrm{O}$ in an ester, typical GSH-lignin \\
1139 & Aromatic C-H in-plane deformation, typical for G unit \\
1117 & Aromatic C-H in-plane deformation, typical for S unit \\
1085 & $\mathrm{C}=$ O deformation in secondary alcohols and aliphatic ethers \\
896 & out-of-plane C-H blending, aromatic \\
\hline
\end{tabular}

The FTIR spectra of wheat straw degraded by Ps and Ps-Ct fermentations (Fig. 5 (b) and (c)) differed from those of alkaline-treated wheat straw (Fig. 5(a)), and FTIR spectra of wheat straw degraded by Ps and Ps-Ct fermentations were similar on the whole. For degraded wheat straw, the band at $1608 \mathrm{~cm}^{-1}$ disappeared, indicating that the aromatic ring conjugated with carbonyl group was cleaved by the oxidation. The band at $1512 \mathrm{~cm}^{-1}$ weakened, suggesting non-conjugated aromatic ring has been cleaved. The band at $1327 \mathrm{~cm}^{-1}$ is a condensed G-S structure (Sun et al., 2005b), which occurred obviously in the FTIR spectra of degraded wheat straw, indicating that lignin polymerization occurred in the fermentation process. The band at $1117 \mathrm{~cm}^{-1}$ is a typical aromatic C-H blending in-plane for S unit (Sun et al., 2005a). The band at $1139 \mathrm{~cm}^{-1}$ (G unit) disappeared in the fermentation while the band at $1117 \mathrm{~cm}^{-1}$ relatively increased, showing that $\mathrm{G}$ unit mainly biodegraded in the fermentations.

\subsection{Proposal Scheme of Biodelignification}

Kirk et al. (1984) studied the dioxane lignin prepared from decayed wood and found that the phenolic hydroxyl content was higher and methoxyl content was lower in the lignin than that in the corresponding lignin from undecayed wood, indicating that demethoxylation and hydroxylation reactions occurred in biodelignification process. Wariishi et al. (1987) found that $48 \% \mathrm{C}_{\alpha}-\mathrm{C}_{\beta}$ bonds were cleaved when studying Syringylglycerol- $\beta$-guaiacyl oxidation by laccase, suggesting that the hydrolysis of $\beta-O-4$ structures was realized by $\mathrm{C}_{\alpha}-\mathrm{C}_{\beta}$ cleavage. Subsequently, 
Ander et al. (1990) identified the products of biodelignification from ring cleavage, $\beta$-O-4 cleavage and 5-5'cleavage by fungi.

Based on the previous studies and results of our experiments, this work proposes a scheme of lignin biodegradation in Ps and Ps-Ct fermentations (Fig. 6). The biodelignification in Ps fermentation is realized by three ways: 1) Ring cleavage. The cleavage of aromatic ring in the lignin was supported by FTIR data. Demethoxylation and hydroxylation reactions occur prior to ring cleavage; 2) $\mathrm{C}_{\alpha}-\mathrm{C}_{\beta}$ and $\beta-\mathrm{O}-4$ cleavage. Ozonation data indicated the cleavage of $\beta-\mathrm{O}-4$ structures. $\mathrm{C}_{\alpha}-\mathrm{C}_{\beta}$ cleavage is prerequisite to precede $\beta-\mathrm{O}-4$ cleavage, the O-C linkage is subsequently cleaved; 3) 5-5' cleavage and polymerization. Alkaline nitrobenzene oxidation data showed the biodegradation of condensed lignin. Biodelignification involves repolymerization reaction as well as degradation reaction. $5-5^{\prime}$ cleavage reaction reduces the proportion of lignin condensation. These three pathways are complementary and promote each other; together they enhanced the lignin macromolecule fragmentation and hydrophilicity, which make the lignin be dissolved. Lignin biodegradation in Ps-Ct fermentation was also realized through the above three pathways. Ps-Ct fermentation enhanced the biodegradation of condensed lignin and $\beta-\mathrm{O}-4$ structures, especially the T-form degradation, by promoting $5-5^{\prime}$ cleavage and $\mathrm{C}_{\alpha}-\mathrm{C}_{\beta}$ cleavage. A study of lignin model compounds on the mechanism promoting Ps biodelignification due to the presence of $C$. tropicalis is underway.

\section{CONCLUSIONS}

P. sanguineus was an effectively lignin-degrading strain with $47.9 \%$ lignin removal of alkali-treated wheat straw; and a 5.0\% lignin removal was increased by the presence of $C$. tropicalis. The biodelignification in Ps and Ps-Ct fermentations can be divided into the fast phase and the following slow phase, which were both pseudo-first-order reactions but different 
bioreaction rate. Ps fermentation mainly biodegraded the uncondensed, $\beta-\mathrm{O}-4$ structures, especially E $\beta-\mathrm{O}-4$ ones in the lignin; Ps-Ct fermentation significantly increased the biodelignification by the more removals of the condensed, $\mathrm{T} \beta-\mathrm{O}-4$ structures and uncondensed $\mathrm{H}$ unit in the lignin due to the presence of $C$. tropicalis. The lignin reaction pathways in Ps and Ps-Ct fermentations mainly may be 1) Ring cleavage, 2) $\mathrm{C}_{\alpha^{-}}-\mathrm{C}_{\beta}$ and $\beta-\mathrm{O}-4$ cleavage, and 3) 5-5' cleavage and polymerization. The mechanism of biodelignification in Ps and Ps-Ct fermentations is different from that in alkaline delignification; an appropriate combination of the two methods will selectively improve the delignification.

\section{ACKNOWLEDGEMENTS}

The authors are grateful for the support of the National Science Foundation of China (Grant No. 31070524), the Major State Basic Research Development Program of China (Grant No. 2010CB732205), the Doctorate Fellowship Foundation of Nanjing Forestry University.

\section{References}

Akiyama, T., Goto, H., Nawawi, D.S., Syafii, W., Matsumoto, Y., Meshitsuka G., 2005.

Erythro/threo ratio of $\beta$-O-4-structures as an important structural characteristic of lignin. Part 4:

Variation in the erythro/threo ratio in softwood and hardwood lignins and its relation to syringyl/guaiacyl ratio. Holzforschung 59(3), 276-281. Doi: 10.1515/HF.2005.045

Akiyama, T., Matsumoto, Y., Okuyama, T., Meshitsuka, G., 2003. Ratio of erythro and threo forms of $\beta-O-4$ structures in tension wood lignin. Phytochemistry 64(6), 1157-1162. Doi:

$10.1016 / \mathrm{S} 0031-9422(03) 00509-0$ 
Ander, P., 1990. Biodegradation of lignin, in: Eriksson, K.E.L., Blanchette, R.A., Ander, P. (Eds.), Microbial and enzymatic degradation of wood and wood components. Methods in lignin chemistry. Springer-Verlag, Berlin, Germany, pp. 249-306. Doi: 10.1007/978-3-642-46687-8 Arzola, K.G., Arévalo, M.C., Falcón, M.A., 2009. Catalytic efficiency of natural and synthetic compounds used as laccase-mediators in oxidising veratryl alcohol and a kraft lignin, estimated by electrochemical analysis. Electrochim. Acta 54(9), 2621-2629. Doi:

10.1016/j.electacta.2008.10.059

Boonyuen, N., Manoch, L., Luangsa-ard, J.J., Piasai, O., Chamswarng, C., Chuaseeharonnachai, C., Ueapattanakit, J., Arnthong, J., Sri-indrasutdhi, V., 2014. Decomposition of sugarcane bagasse with lignocellulose-derived thermotolerant and thermoresistant Penicillia and Aspergilli. Int. Biodeter. Biodegr. 92, 86-100. Doi: 10.1016/j.ibiod.2014.04.013

Camarero, S., Martínez, M.J., Martínez, A.T., 2014. Understanding lignin biodegradation for the improved utilization of plant biomass in modern biorefineries. Biofuel. Bioprod. Bior. 8(5), 615-625. Doi: 10.1002/bbb.1467

Cañas, A.I., Camarero, S., 2010. Laccases and their natural mediators: biotechnological tools for sustainable eco-friendly processes. Biotechnol. Adv. 28(6), 694-705. Doi:

10.1016/j.biotechadv.2010.05.002

Chang, H.M., Allan, G.G., 1971. Oxidation, in: Sarkanen, K.V., Ludwig, C.H. (Eds.), Lignins: occurrence, formation, structure and reactions. Wiley-Interscience, New York, pp. 433-485. Chen, C.L., 1992. Nitrobenzene and Cupric Oxide Oxidations, in: Lin, S.Y., Dence, C.W. (Eds.), Methods in lignin chemistry. Springer-Verlag, Berlin, Germany, pp. 301-321. Doi: 
$10.1007 / 978-3-642-74065-7$

Crawford, R.L., Crawford, D.L., 1984. Recent advances in studies of the mechanisms of microbial degradation of lignins. Enzyme Microb. Tech. 6(10), 434-442. Doi:

$10.1016 / 0141-0229(84) 90092-9$

Eggert, C., Temp, U., Dean, J.F., Eriksson, K.E.L., 1996. A fungal metabolite mediates degradation of non-phenolic lignin structures and synthetic lignin by laccase. FEBS Lett. 391(1), 144-148. Doi: 10.1016/0014-5793(96)00719-3

Eggert, C., Temp, U., Dean, J.F., Eriksson, K.E.L., 1995. Laccase-mediated formation of the phenoxazinone derivative, cinnabarinic acid. FEBS Lett. 376(3), 202-206. Doi:

$10.1016 / 0014-5793(95) 01274-9$

Feng, N.J., Ma, Q.Z., Yuan, M.T., Zhai, H.M., Ek, Monica, 2015. Improving degradation ability toward wheat straw chemical composition by co-cultivation of Pycnoporus sanguineus with Candida tropicalis. J. Biobased Mater. Bio. 9(6), 567-571. DOI: 10.1166/jbmb.2015.1555

Feng, N.J, Zhai, H.M., Wang, C.H., 2014. Identification and Lignin Degradation of Pycnoporus sanguineus Strain NFZH-1 with an Endogenous Mediator. Chem. Ind. Forest Prod. 34(5), 1-7. Doi: $10.3969 /$ j.issn.0253-2417.2014.05.001

Freudenberg, K., 1959. Biosynthesis and constitution of lignin. Nature 183(4669), 1152-1155. Doi: $10.1038 / 1831152 \mathrm{a} 0$

Himmel, M.E., Ding, S.Y., Johnson, D.K., Adney, W.S., Nimlos, M.R., Brady, J.W., Foust, T.D., 2007. Biomass recalcitrance: Engineering plants and enzymes for biofuels production. Science 315(5813), 804-804. Doi: 10.1126/science.1137016 
Kleppe, P.J., 1970. Kraft pulping. Tappi J. 53(1), 35-47.

Kirk, T.K., Tien, M., Faison, B.D., 1984. Biochemistry of the oxidation of lignin by

Phangerochate chrysosporium. Biotechnol. Adv. 2(2), 183-199. Doi:

$10.1016 / 0734-9750(84) 90004-1$

Ma, P., Fu, S.L., Zhai, H.M., Law, K., Daneault, C., 2012. Influence of TEMPO-mediated oxidation on the lignin of thermomechanical pulp. Bioresource Technol. 118, 607-610. Doi:

10.1016/j.biotech.2012.05.037

Marton, J., 1971. Reactions in Alkaline Pulping, in: Sarkanen, K.V., Ludwig, C.H. (Eds.), Lignins: occurrence, formation, structure and reactions. Wiley-Interscience, New York, pp. 639-694.

Menon, V., Rao, M., 2012. Trends in bioconversion of lignocelluloses: Biofuels, platform chemicals and biorefinery concept. Prog. Energ. Combust. 38(4), 522-550. Doi:

10.1016/j.pecs.2012.02.002

Munk, L., Sitarz, A.K., Kalyani, D.C., Mikkelsen, J.D., Meyer, A.S., 2015. Can laccases catalyze bond cleavage in lignin?. Biotechnol. Adv. 33(1), 13-24. Doi: 10.1016/j.biotechadv.2014.12.008

Niu, K., Chen, P., Zhang, X., Tan, W.S., 2009. Enhanced enzymatic hydrolysis of rice straw pretreated by alkali assisted with photocatalysis technology. J. Chem. Technol. Biot. 84(8), 1240-1245. Doi: $10.1002 /$ jctb. 2185

Pandey, K.K., Pitman, A.J., 2003. FTIR studies of the changes in wood chemistry following decay by brown-rot and white-rot fungi. Int. Biodeter. Biodegr. 52(3), 151-160. Doi:

10.1016/S0964-8305(03)00052-0 
Rebek, J., 2005. Simultaneous encapsulation: Molecules held at close range. Angew. Chem. Int. Ed. 44, 2068-2078. Doi: 10.1002/anie.200462839

Roberto, I.C., Mussatto, S.I., Rodrigues, R.C.L.B., 2003. Dilute-acid hydrolysis for optimization of xylose recovery from rice straw in a semi-pilot reactor. Ind. Crop. Prod. 17(3), 171-176. Doi: 10.1016/S0926-6690(02)00095-X

Sarkanen, K.V., Islam, A., Anderson, C.D., 1992. Ozonation, in: Lin, S.Y., Dence, C.W. (Eds.), Methods in lignin chemistry. Springer-Verlag, Berlin, Germany, pp. 301-321. Doi: $10.1007 / 978-3-642-74065-7$

Siqueira, G., Várnai, A., Ferraz, A., Milagres, A.M.F., 2013. Enhancement of cellulose hydrolysis in sugarcane bagasse by the selective removal of lignin with sodium chlorite. Appl. Energ. 102(2), 399-402. Doi: 10.1016/j.apenergy.2012.07.029

Shimizu, S., Yokoyama, T., Akiyama, T., Matsumoto, Y., 2012. Reactivity of Lignin with Different Composition of Aromatic Syringyl/Guaiacyl Structures and Erythro/Threo Side Chain Structures in $\beta-O-4$ Type during Alkaline Delignification: As a Basis for the Different Degradability of Hardwood and Softwood Lignin. J. Agr. Food Chem. 60(26), 6471-6476. Doi: $10.1021 / \mathrm{jf} 301329 \mathrm{v}$

Sun, X.F., Sun, R.C., Fowler, P., Baird, M.S., 2005a. Extraction and characterization of original lignin and hemicelluloses from wheat straw. J. Agr. Food Chem. 53(4), 860-870. Doi:

$10.1021 / \mathrm{jf040456q}$

Sun, X.F., Xu, F., Sun, R.C., Fowler, P. Baird, M.S., 2005b. Characteristics of degraded cellulose obtained from steam-exploded wheat straw. Carbohyd. Res. 340(1), 97-106. Doi: 
10.1016/j.carres.2004.10.022

TAPPI Committee, 1995. TAPPI Test Methods (1994-1995), TAPPI Press, Atlanta, GA, USA.

Tejado, A., Peña, C., Labidi, J., Echeverria, J.M., Mondragon, I., 2007. Physico-chemical

characterization of lignins from different sources for use in phenol-formaldehyde resin synthesis.

Bioresource Technol. 98(8), 1655-1663. Doi: 10.1016/j.biortech.2006.06.042

Ueda, C., Takashima, Y., Ishiguri, F., 2015. Ozone oxidation pretreatment for enzymatic

saccharification of spent culture media after Lentinula edodes cultivation. J. Wood Sci. 61, 65-69.

Doi: 10.1007/s10086-014-1441-z

Wariishi, H., Morohoshi, N., Haraguchi, T., 1987. Degradation of lignin by laccase isolated from

Coriolus versicolor. Mokuzai Gakkaishi 11, 892-898.

Zhai, H.M., Lee, Z.Z., Tai, D.S., 1992. Characteristics of the Fiber Cell and Parenchyma Cell

Lignins from Wheat Straw. China Pulp Pap. 1, 18-21.

Zhang, X.Y., Yu, H.B., Huang, H.Y., Liu, Y.X., 2007. Evaluation of biological pretreatment with white rot fungi for the enzymatic hydrolysis of bamboo culms. Int. Biodeter. Biodegr. 60(3),

159-164. Doi: 10.1016/j.ibiod.2007.02.003 


\section{Figure captions}

Figure 1. Biodelignification of wheat straw in Ps and Ps-Ct fermentations.

Figure 2. Kinetic curve of biodelignification in Ps and Ps-Ct fermentations.

Figure 3. The yield and ratio of nitrobenzene oxidation products in $\mathrm{Ps}$ and $\mathrm{Ps}-\mathrm{Ct}$

fermentations, including NOP (a), G (b), S (c), S/G (d), H (e) and H/G (f).

Figure 4. The yield and ratio of ozonation products in Ps and Ps-Ct fermentations, including E+T (a), E (b), T (c) and E/T (d).

Figure 5. FTIR spectra of alkaline-treated wheat straw (a), alkaline-treated wheat straw degraded by Ps fermentation for 40 days (b), alkaline-treated wheat straw degraded by Ps-Ct fermentation for 40 days (c).

Figure 6. The proposal scheme of biodelignification in Ps and Ps-Ct fermentations. Bold type represents the cleavages are intensified by Ps-Ct fermentation, and L denotes the lignin residue. 


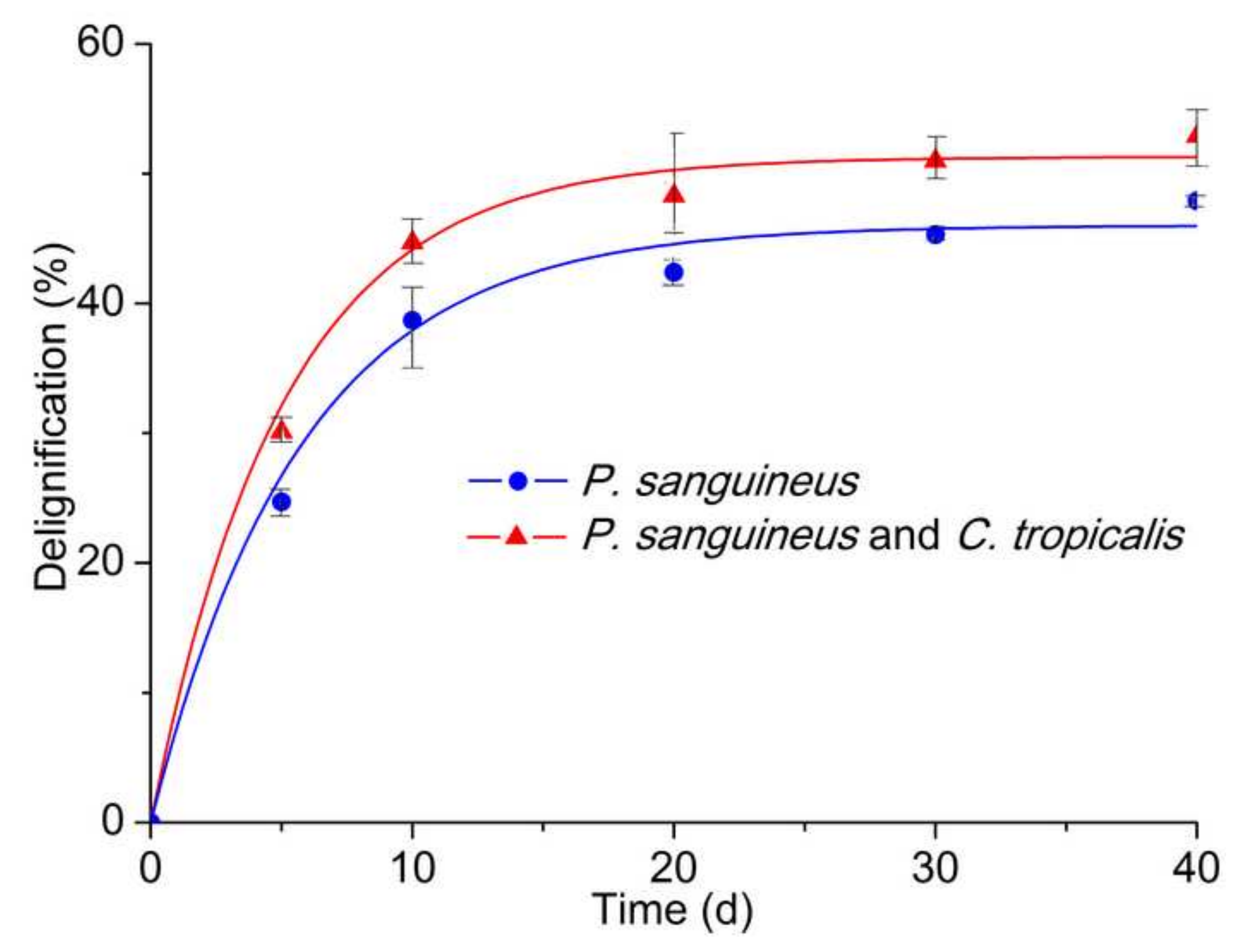




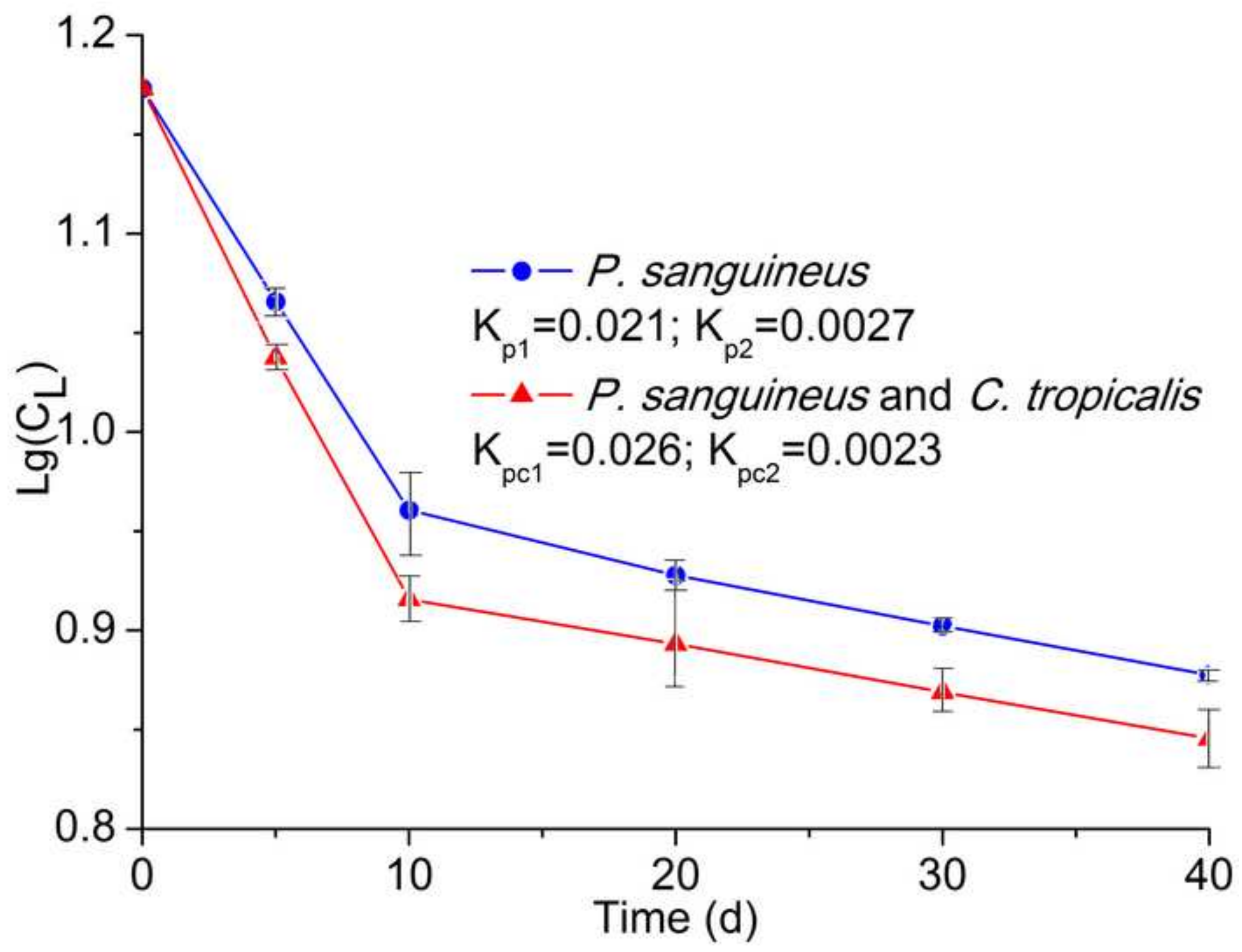

- $P$. sanguineus

$\mathrm{K}_{\mathrm{p} 1}=0.021 ; \mathrm{K}_{\mathrm{p} 2}=0.0027$

$-\Delta-P$. sanguineus and $C$. tropicalis

$\mathrm{K}_{\mathrm{pc} 1}=0.026 ; \mathrm{K}_{\mathrm{pc} 2}=0.0023$

Time (d) 

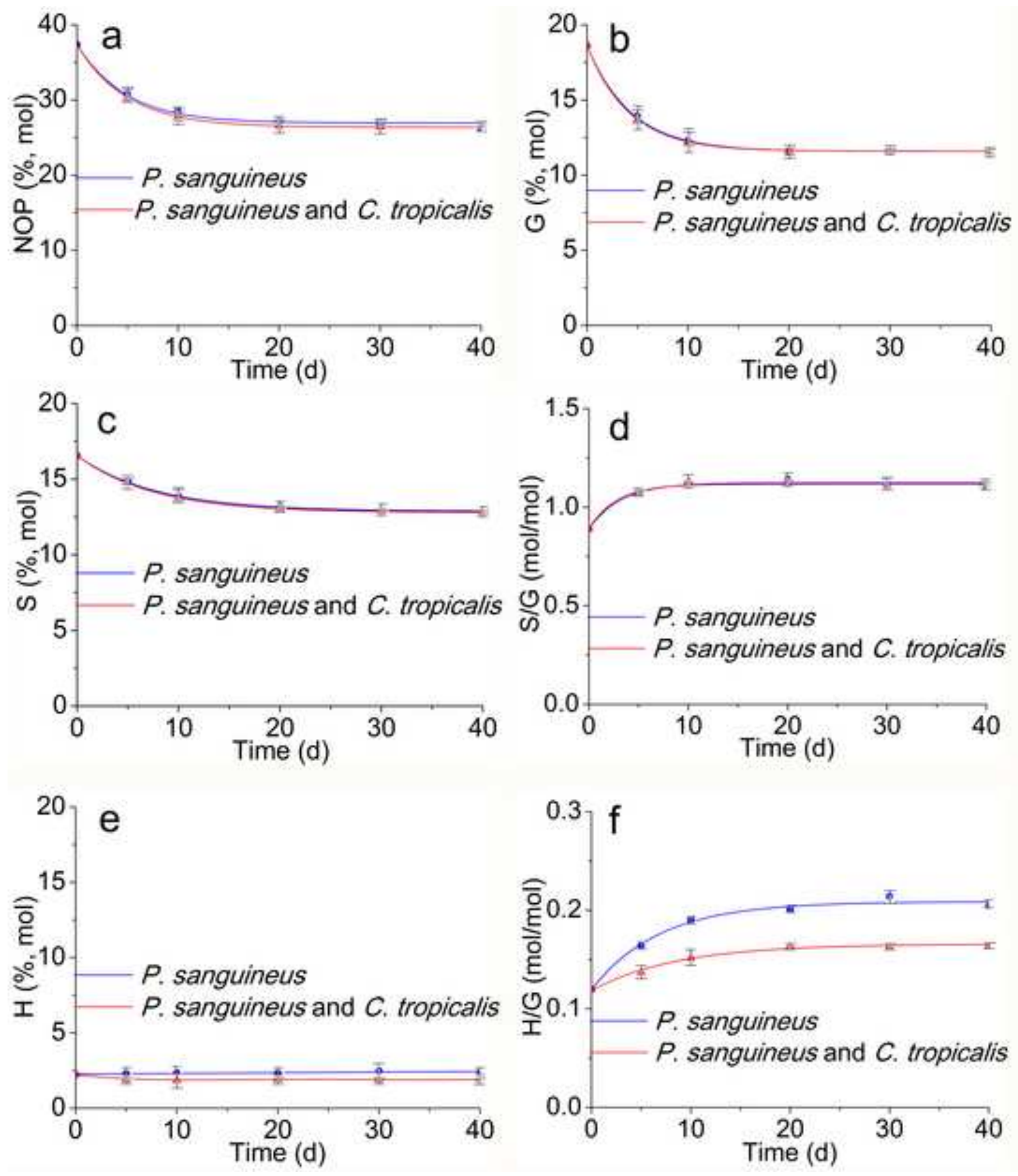

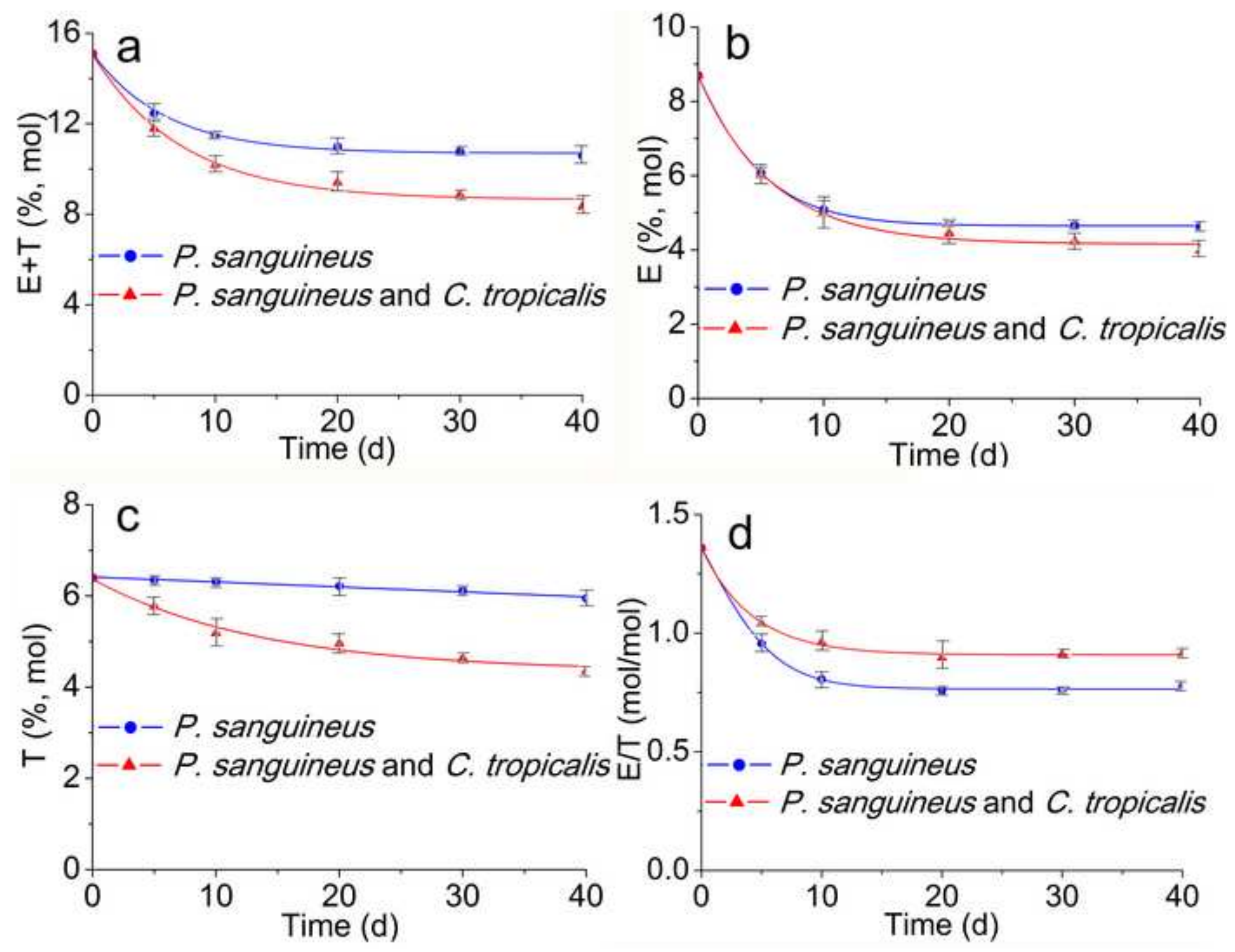


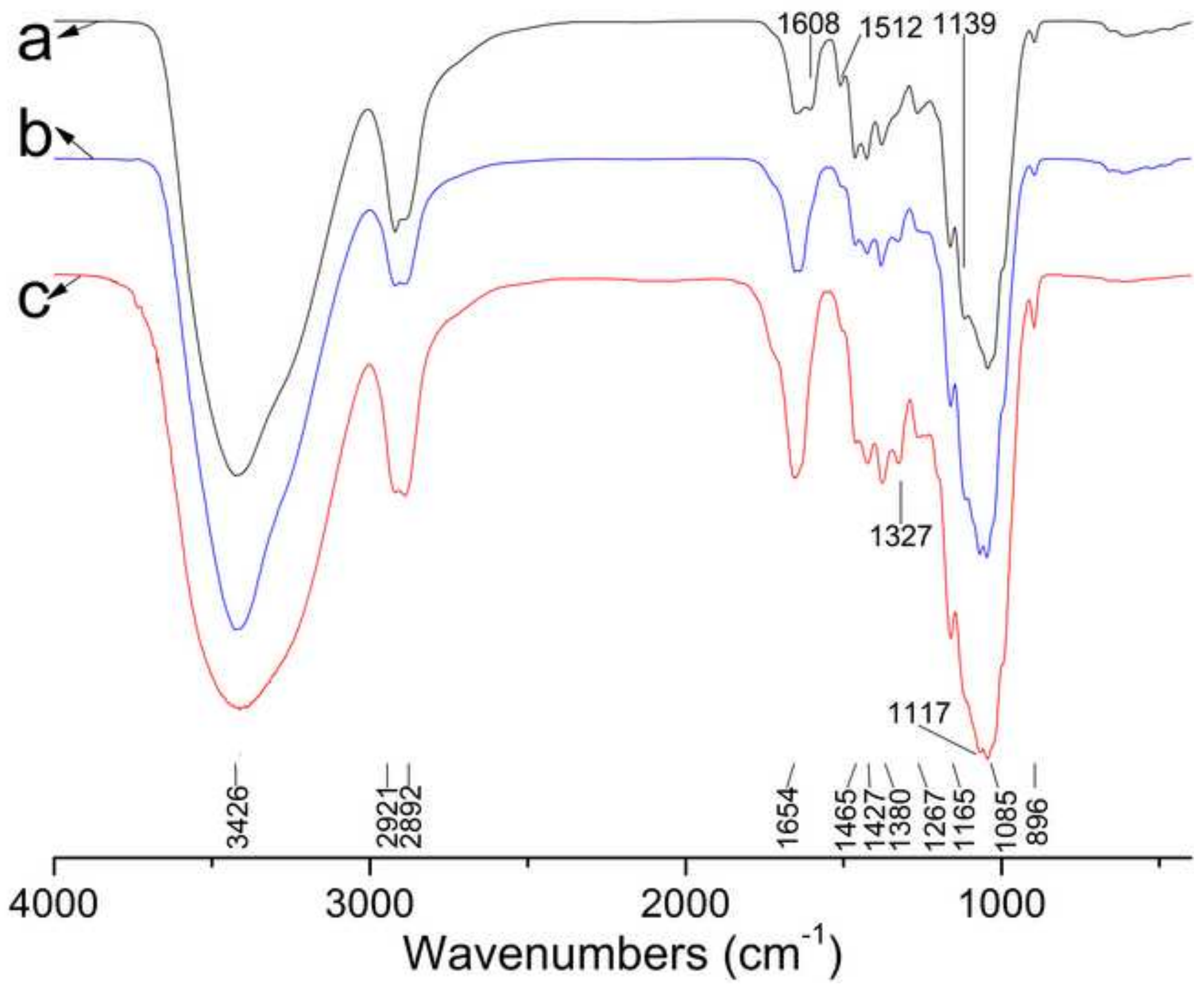




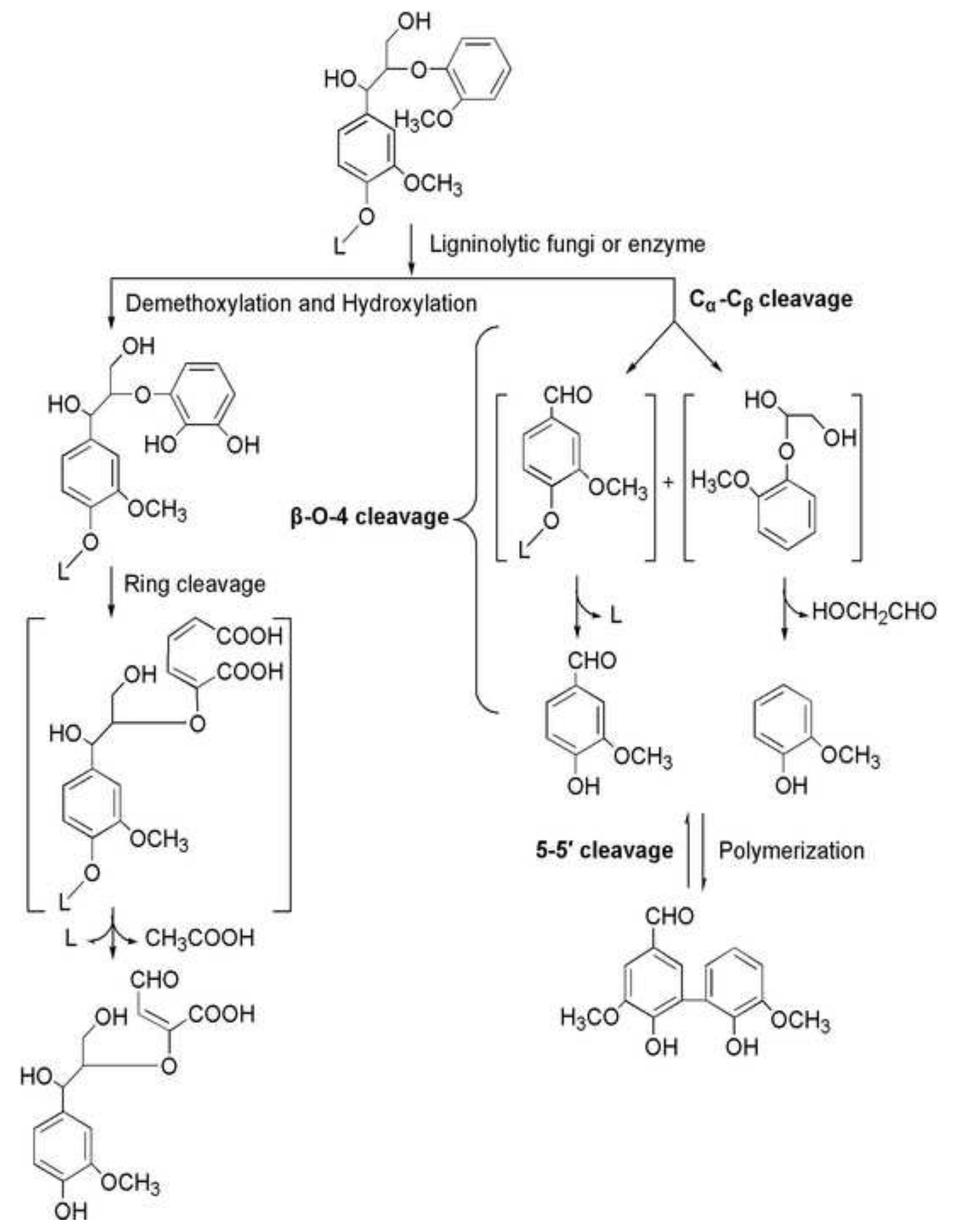




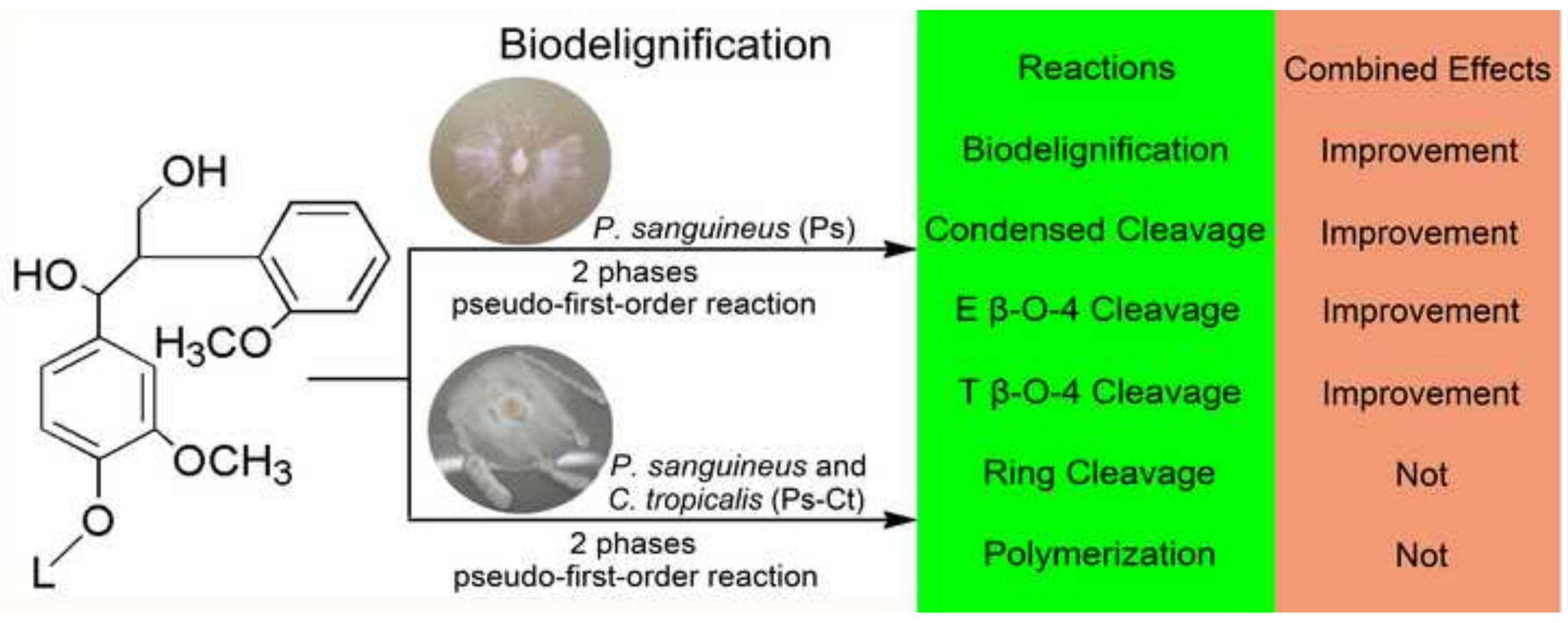

